\title{
6-位修饰的吉非替尼衍生物合成及细胞毒活性研究
}

\author{
沈明辉 ${ }^{a}$ 陈仕杰 ${ }^{a}$ 王雪微 ${ }^{a}$ 龚显峰*, $a, b$ 张 华*, $a, b$ \\ ( ${ }^{a}$ 黑龙江大学功能有机重点实验室 哈尔滨 150080) \\ ${ }^{b}$ 国药一心制药有限公司 长春 130012)
}

\begin{abstract}
摘要 以 2-氨基-4,5-二甲氧基苯甲酸为起始原料, 经关环, 选择性脱甲基，醋酸酐保护，氯代，与 3-氯-4-氟苯胺取代, 去保护得到关键中间体 4-(3-氯-4-氟苯胺)-7-甲氧基-喹唑啉-6-醇. 再经过 6-位羟基成醚、成酯反应合成了共计 23 个吉 非替尼衍生物. 所有目标化合物通过 IR, ${ }^{1} \mathrm{H}$ NMR, ${ }^{13} \mathrm{C}$ NMR, HRMS 等结构确证. 并采用四甲基偶氮唑盐(MTT)法对所 得目标化合物进行了细胞毒活性测试，结果发现部分化合物具有一定的抑制活性，其中化合物 7b, 7c, 7d, 8a, 8m 抑制 人非小细胞肺癌细胞(A549)增殖活性和化合物 7c, 8m 抑制人肝癌细胞(HepG-2)增殖活性与吉非替尼相当.

关键词 吉非替尼衍生物; 合成; MTT 法
\end{abstract}

\section{Synthesis and Cytotoxic Activity of 6-Modified Gefitinib Derivatives}

\author{
Shen, Minghui ${ }^{a} \quad$ Chen, Shijie $^{a} \quad$ Wang, Xuewei $^{a} \quad$ Gong, Xianfeng ${ }^{*, a, b} \quad$ Zhang, Hua ${ }^{*, a, b}$ \\ ( ${ }^{a}$ Key Laboratory of Applied Organic, Heilongjiang University, Harbin 150080) \\ ( ${ }^{b}$ Sinopharm A-Think Pharmaceuticals Co., Ltd., Changchun 130012)
}

\begin{abstract}
Twenty-three derivatives of gefitinib have been synthesized by etherification and esterification of 4-(3-chloro-4-fluoroanilino)-6-hydroxy-7-methoxy quinazoline, which was prepared from 2-amino-4,5-dimethoxy-benzoic acid through the reactions of cyclization, selective demethylation, acetyl protection, chlorination, substitution with 3-chloro4-fluoro-benzenamine and deprotection, respectively. The structures of the target compounds were characterized by IR, ${ }^{1} \mathrm{H}$ $\mathrm{NMR},{ }^{13} \mathrm{C}$ NMR and HRMS spectra. All the title compounds were evaluated for cytotoxic activity against human non-small-cell-lung cancer cells lines (A549) and human hepatoma cell lines (HepG2) by methyl thiazolyl tetrazolium (MTT) method. The results showed that the cytotoxic activities of compounds $\mathbf{7 b}, \mathbf{7 c}, \mathbf{7 d}, \mathbf{8 a}, \mathbf{8 m}$ against human non-small-cell-lung cancer cells lines and compounds $\mathbf{7 c}, \mathbf{8 m}$ against human hepatoma cell lines were comparable to those of gifitinib.
\end{abstract}

Keywords gefitinib derivatives; synthesis; MTT assay

吉非替尼(商品名：易瑞沙，Iressa ${ }^{\mathrm{TM}}$ ，图 1)，由阿斯 利康公司研制的第一个表皮生长因子受体酪氨酸激酶 抑制剂, 其化学名为 4-(3-氯-4-氟苯胺基)-7-甲氧基6-(3-吗琳基丙氧基)喹唑啉, 2002 年 7 月首次在日本上 市 $^{[1 \sim 5]}$. 主要用于非小细胞肺癌的治疗, 其作用机制主 要是抑制酪氨酸激酶表皮生长因子受体(EGFR), 以 EGFR 为作用靶点通过与 EGFR 的三磷酸腺苷(ATP)结 合位点上高度保守的 ATP 竞争性结合 $\mathrm{EGFR}^{[6,7]}$; 对 EGF 受体有抑制作用 ${ }^{[8 \sim 12]}$; 促进细胞调亡; 并能抑制肿瘤血 管生成. 具有十分广阔的临床应用前景. 但是, 随着吉 非替尼的上市使用, 相继产生了耐药性等问题 ${ }^{[13]}$, 因此 合成吉非替尼衍生物, 研究开发吉非替尼 “me-too” 或 “me-better” 药物具有十分重要意义.<smiles>COc1cc2ncnc(Nc3ccc(F)c(Cl)c3)c2cc1OCCCN1CCOCC1</smiles>

图 1 吉非替尼的结构

Figure 1 Structure of gefitinib

本文参考文献 $[14 \sim 16]$ 的合成方法，以 2-氨基-4,5二甲氧基苯甲酸为起始原料经关环，选择性脱甲基，醋 酸䣶保护, 氯代, 与 3-氯-4-氟苯胺反应, 去保护得到关

\footnotetext{
*E-mail: zhanghua34@163.com

Received March 22, 2015; revised April 20, 2015; published online April 30, 2015.

Project supported by the Foundation of Heilongiiang Educational Committee.

黑龙江省教育厅科学技术研究资助项目.
} 
键中间体 4-(3-氯-4-氟苯胺)-7-甲氧基-喹唑啉-6-醇(6), 再通过 6-位羟基成醚、成酯反应合成 6-位不同取代的吉 非替尼衍生物(Scheme 1). 中间体 6 与取代的对甲苯磺 酸酯、 $\alpha$-氯代酰胺反应成醚时, 以 $\mathrm{DMF}$ 为溶剂, $\mathrm{K}_{2} \mathrm{CO}_{3}$ 为催化剂, 反应温度 $75 \sim 80{ }^{\circ} \mathrm{C}$, 加入少量 $\mathrm{KI}$ 可以明显 加快反应速度，一般反应 $3 \sim 6 \mathrm{~h}$, 收率可达 $60 \% \sim 80 \%$. 而中间体 6 与 $N$-乙酰化氨基酸或二肽缩合成酯时, 用 $O$-苯并三唑- $N, N, N, N$-四甲基脲四氟硼酸酯(TBTU)为缩 合剂, 室温下反应 $8 \sim 10 \mathrm{~h}$, 收率较高. 所有目标化合物
均经过 IR, ${ }^{1} \mathrm{H}$ NMR, ${ }^{13} \mathrm{C}$ NMR, HRMS 结构确证，并采用 四甲基偶氮唑盐(MTT)法测试目标化合物细胞毒活性.

\section{1 结果与讨论}

\section{1 波谱解析}

以目标化合物 $7 \mathrm{a}, 8 \mathrm{a}, 9 \mathrm{a}$ 的光谱数据分析为例. 对 于化合物 7a 的 ${ }^{1} \mathrm{H}$ NMR 中 $\delta 8.66$ 处的单峰为喹唑啉 2位碳原子上质子 $\mathrm{H}$ 信号峰； $\delta 7.08 \sim 7.90$ 为苯环碳原子
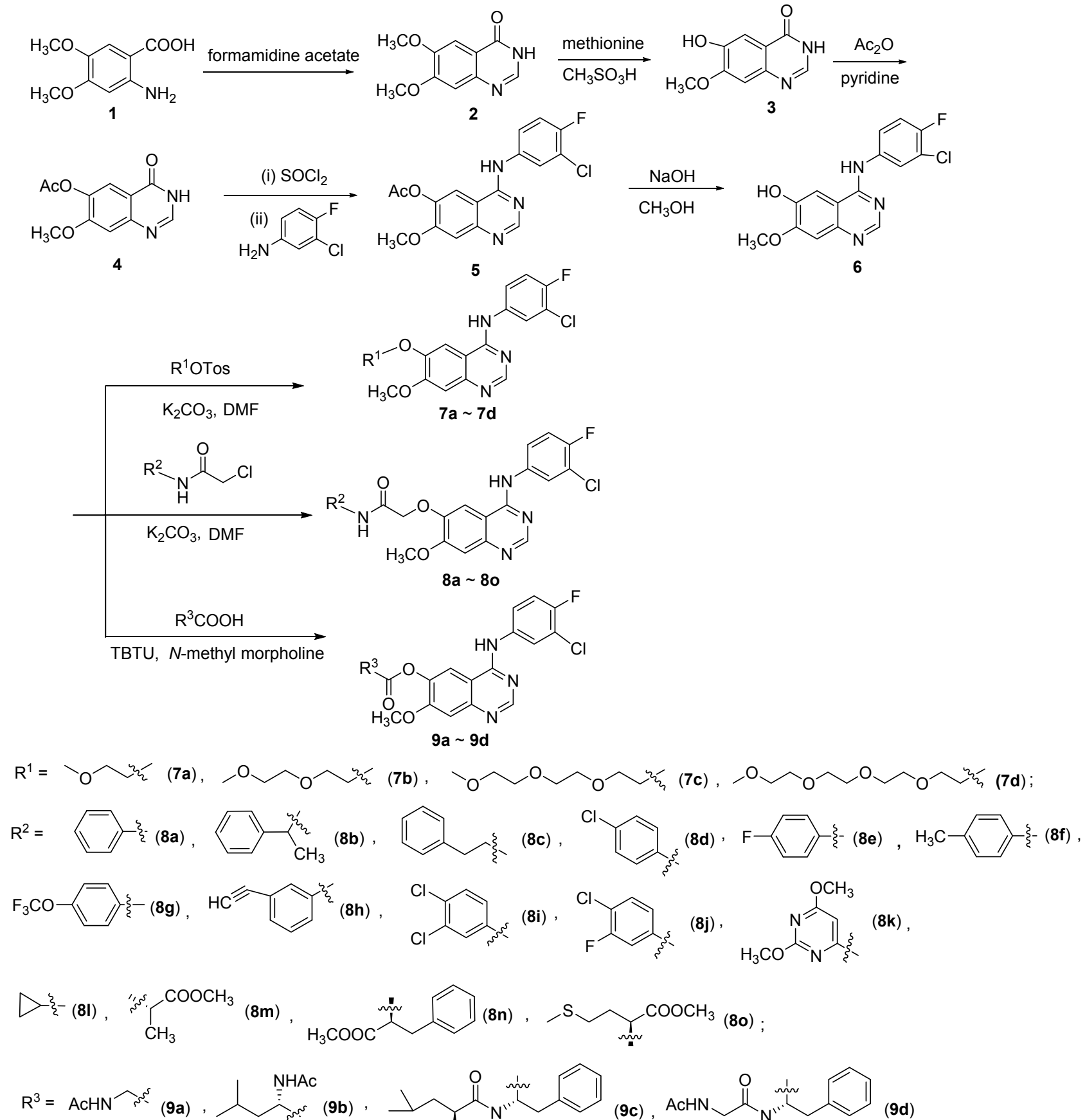

(9a)<smiles>CC(C)C[C@H](N)C(C)C</smiles><smiles>C1CCCCC1</smiles><smiles>CC(C)CC(N)C(=O)NC(C)(C)Cc1ccccc1</smiles>

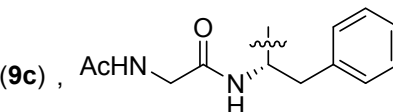
(9d)

图式 16 -位修饰的吉非替尼衍生物的合成

Scheme 1 Synthesis of 6-modified gefitinib derivatives 
上质子 $\mathrm{H}$ 信号峰; $\delta 3.88$ 处的单峰为 7-位甲氧基碳原子 上质子 $\mathrm{H}$ 信号峰; $\delta 3.49$ 处的单峰为 6-位侧链末端甲氧 基碳原子上质子 $\mathrm{H}$ 信号峰. 分子结构中存在四个脂肪碳 $\delta: 56.2,59.4,68.0,69.1$; 十四个芳环碳 $\delta: 101.4,108.2$, 109.2 , 116.0, 116.5, 120., 124.0, 135.2, 135.3, 147.8, $149.0,153.6,155.4,156.1$. 其红外光谱图中 $3346 \mathrm{~cm}^{-1}$ 处 有吸收峰说明分子中有仲胺存在; $3120 \mathrm{~cm}^{-1}$ 为苯环 $\mathrm{C}$ $\mathrm{H}$ 伸缩振动吸收峰, $2929.8 \mathrm{~cm}^{-1}$ 为侧链甲基或亚甲基 $\mathrm{C}$ - $\mathrm{H}$ 伸缩振动吸收峰, $1640,1577,1502,1425 \mathrm{~cm}^{-1}$ 为 苯环 $\mathrm{C}=\mathrm{C}$ 伸缩振动吸收峰, $1223 \mathrm{~cm}^{-1}$ 为醚键 $\mathrm{C}-\mathrm{O}$ 伸 缩振动吸收. 高分辨质谱 HRMS (ESI-MS) calcd for $\mathrm{C}_{18} \mathrm{H}_{17} \mathrm{ClFN}_{3} \mathrm{O}_{3}[\mathrm{M}+\mathrm{H}]^{+}$378.0992, found 378.0996. 说 明分子量正确. 综合 ${ }^{1} \mathrm{H} N M R,{ }^{13} \mathrm{C} N M R, I R, H R M S$ 等光 谱数据, 可以充分说明其结构的正确性.

对于化合物 8a 的 ${ }^{1} \mathrm{H}$ NMR 中 $\delta 10.6$ 处的单峰为喹 唑啉 6-位侧链酰胺键的质子 $\mathrm{H}$ 信号峰; $\delta 9.58$ 为肿胺质 子 $\mathrm{H}$ 信号峰; $\delta 8.53$ 为喹唑啉环上 2 -位质子 $\mathrm{H}$ 信号峰; $\delta$ $7.09 \sim 7.95$ 为苯环碳原子质子 $\mathrm{H}$ 信号峰; $\delta 4.89$ 为侧链亚 甲基单峰, $\delta 4.00$ 处单峰为 7-位甲氧基碳原子上质子 $\mathrm{H}$ 信号峰. 分子结构中存在两个脂肪碳 $\delta: 56.5,69.1$; 二十 个芳环碳 $\delta: 156.7,155.0,154.90,153.5,152.5,148.0$, $138.7,137.2,129.3,124.3,124.0,122.8,120.1,119.3$, $116.9,109.1,108.1,104.7$; 一个羰基碳 $\delta: 166.3$. 其红外 光谱图中, $3394 \mathrm{~cm}^{-1}$ 处有单峰说明分子中有仲胺基; $3004 \mathrm{~cm}^{-1}$ 为苯环 $\mathrm{C}-\mathrm{H}$ 振动吸收峰; $1673 \mathrm{~cm}^{-1}$ 为酰胺 键 $\mathrm{C}=\mathrm{O}$ 伸缩振动吸收峰; $1631,1504,1434 \mathrm{~cm}^{-1}$ 为苯环 $\mathrm{C}=\mathrm{C}$ 伸缩振动吸收峰, $1198 \mathrm{~cm}^{-1}$ 醚键 $\mathrm{C}-\mathrm{O}$ 伸缩振动 吸收峰。高分辨质谱 HRMS (ESI-MS) calcd for $\mathrm{C}_{23} \mathrm{H}_{18} \mathrm{ClFN}_{4} \mathrm{O}_{3}[\mathrm{M}+\mathrm{H}]^{+}$453.1131, found 453.1132. 说 明分子量正确. 综合 ${ }^{1} \mathrm{H} N M R,{ }^{13} \mathrm{C} N M R$, IR, HRMS 等光 谱数据, 可以充分说明其结构的正确性.

对于化合物 9a 的 ${ }^{1} \mathrm{H}$ NMR 中 $\delta 9.75$ 处的单峰为喹 唑啉 6-位侧链酰胺键的质子 $\mathrm{H}$ 信号峰; $\delta 8.59$ 为肿胺质 子 $\mathrm{H}$ 信号峰; $\delta 8.31$ 喹唑啉环上 2-位质子 $\mathrm{H}$ 信号峰, $\delta$ $7.36 \sim 8.18$ 为苯环碳原子上质子 $\mathrm{H}$ 信号峰; $\delta 4.19 \sim 4.20$ 为侧链亚甲基质子 $\mathrm{H}$ 信号峰; $\delta 3.93$ 处单峰为 7-位甲氧 基碳原子上质子 $\mathrm{H}$ 信号峰; $\delta 1.91$ 处单峰为甲基上质子 $\mathrm{H}$ 信号峰. 分子结构中存在三个脂肪碳 $\delta: 22.7,56.9$; 十 四个芳环碳 $\delta: 157.3,155.8,155.2,150.7,139.4,137.1$, $123.8,122.6,119.4,119.2,117.2,116.9,116.5,109.1$; 两 个羰基碳 $\delta: 170.4,169.1$. 红外光谱中 $3401 \mathrm{~cm}^{-1}$ 处有单 峰说明分子中有仲胺基; $3123 \mathrm{~cm}^{-1}$ 为苯环 $\mathrm{C}-\mathrm{H}$ 振动吸 收峰; $1760 \mathrm{~cm}^{-1}$ 酯羰基的伸缩振动峰; $1630 \mathrm{~cm}^{-1}$ 为酰 胺键羰基的伸缩振动峰; $1499,1427 \mathrm{~cm}^{-1}$ 为苯环 $\mathrm{C}=\mathrm{C}$ 伸缩振动吸收峰; $1164 \mathrm{~cm}^{-1}$ 醚键 $\mathrm{C}-\mathrm{O}$ 伸缩振动吸收峰.
高分辨质谱 $\mathrm{HRMS}$ (ESI-MS) calcd for $\mathrm{C}_{20} \mathrm{H}_{18} \mathrm{ClFN}_{4} \mathrm{O}_{5}$ $[\mathrm{M}+\mathrm{H}]^{+}$419.0924, found 419.0920. 说明分子量正确. 综合 ${ }^{1} \mathrm{H} N M R,{ }^{13} \mathrm{C} N M R, I R, H R M S$ 等光谱数据, 可以充 分说明其结构的正确性.

\section{2 生物活性测试结果与讨论}

采用 MTT 比色法考察 23 个目标化合物对体外培养 的人非小细胞肺癌细胞(A549)和人肝癌细胞(HepG-2)生 长的抑制作用，结果发现 6-位接直链醚类化合物 7a 7d 抑制非小细胞肺癌细胞(A549)生长活性均较高, 其 中化合物 7b、7c 抑制非小细胞肺癌(A549)生长活性高 于对照品吉非踢尼. 而 6-位以酰胺醚相连接的化合物抑 制活性较小，芳酰胺醚比脂肪酰胺醚类化合物抑制活性 较高, 其芳酰胺中芳环上无取代或有吸电子取代的化合 物抑制活性较高. 其中化合物 8a、8m 抑制非小细胞肺 癌细胞(A549)生长活性高于对照品吉非替尼，6-位成酯 接入氨基酸或二肽的化合物 9a $\sim 9 d$ 抑制活性均较小. 此 6-位修饰的吉非替尼衍生物对人肝癌细胞(HepG-2) 生长的抑制作用均较小，只有化合物 7c、8m 表现出一 定的对人肝癌细胞(HepG-2)生长抑制作用(表 1).

表 1 目标化合物体外对人 A549 肺癌细胞和 HepG-2 肝癌细 胞的抑制活性

Table 1 Inhibitory activity of target compounds against K562 and HEPG-2 cell growth in vitro

\begin{tabular}{ccc}
\hline \multirow{2}{*}{ Compd. } & \multicolumn{2}{c}{$\mathrm{IC}_{50}$ 值 $/\left(\mu \mathrm{mol} \cdot \mathrm{L}^{-1}\right)$} \\
\cline { 2 - 3 } 7a & $\mathrm{A} 549$ & $\mathrm{HepG}-2$ \\
$\mathbf{7 b}$ & 40.450 & 11.345 \\
$\mathbf{7 c}$ & 38.670 & 21.674 \\
$\mathbf{7 d}$ & 55.600 & 8.670 \\
$\mathbf{8 a}$ & 40.345 & 18.344 \\
$\mathbf{8 b}$ & $>500$ & 13.065 \\
$\mathbf{8 c}$ & $>500$ & $>100$ \\
$\mathbf{8 d}$ & $>500$ & $>100$ \\
$\mathbf{8 e}$ & $>500$ & $>100$ \\
$\mathbf{8 f}$ & $>500$ & $>100$ \\
$\mathbf{8 g}$ & 86.765 & $>100$ \\
$\mathbf{8 h}$ & 150.124 & 19.694 \\
$\mathbf{8 i}$ & 49.456 & 30.190 \\
$\mathbf{8 j}$ & 50.867 & 12.456 \\
$\mathbf{8 k}$ & $>500$ & 20.134 \\
$\mathbf{8 1}$ & $>500$ & $>100$ \\
$\mathbf{8 m}$ & 36.345 & $>100$ \\
$\mathbf{8 n}$ & $>500$ & 7.567 \\
$\mathbf{8 0}$ & $>500$ & $>100$ \\
$\mathbf{9 a}$ & 67.436 & $>100$ \\
$\mathbf{9 b}$ & 88.670 & 30.456 \\
$\mathbf{9 c}$ & $>500$ & 17.543 \\
$\mathbf{9 d}$ & $>500$ & $>100$ \\
$\mathrm{Gifitinib}$ & 45.746 & $>100$ \\
\hline & & 6.032 \\
\hline & &
\end{tabular}




\section{2 结论}

该 6-位修饰的吉非替尼衍生物对人肝癌细胞 (HepG-2)生长抑制作用均较小, 只有化合物 7c, $8 \mathbf{m}$ 表现 出一定的对人肝癌细胞(HepG-2)生长的抑制作用. 化合 物 7a 7d, 8a, 8i, 8j, 8m 具有一定的抑制非小细胞肺癌 细胞(A549)生长活性, 其中 $\mathbf{7 b}, \mathbf{7 c}, \mathbf{8 a}, \mathbf{8 m}$ 抑制非小细胞 肺癌细胞(A549)生长活性高于对照品吉非替尼.

\section{3 实验部分}

\section{1 仪器与试剂}

红外光谱仪为 Spectrum One (溴化钾压片); 核磁共 振光谱仪为 BrukerAvance III400 (TMS 为内标, $\mathrm{CDCl}_{3}$ 或 DMSO- $d_{6}$ 为溶剂); 高分辨质谱仪为 micrOTOF-Q II10203; X-4 型数显显微熔点测定仪(温度计未校正); 氨基酸甲酯盐酸盐和 $N$-乙酰化甘氨基酸, $N$-乙酰化亮氨 酸(纯度 $99 \%$, 上海瀚鸿化工科技有限公司), 对甲苯磺 酸酯 (ROTos) 和二 肽 AcHN-Leu-Phe-COOH 和 AcHN-Leu-Gly-COOH(纯度 $99 \%$, 百灵威科技有限公 司), 吉非替尼对照品(国药一心制药有限公司提供), 实 验中其他化学试剂和原料均为化学纯或分析纯.

\subsection{6,7-二甲氧基喹唑啉-4-酮(2)的合成}

参考文献[15]合成，白色固体，收率 90\%, m.p.> $230{ }^{\circ} \mathrm{C}$ (文献[15], 收率 79\%, m.p. 295 298 ${ }^{\circ} \mathrm{C}$ ).

\subsection{6-羟基-7-甲氧基喹唑啉-4-酮(3)的合成}

参考文献 $[15,16]$ 合成, 灰色固体, 收率 $40.5 \%$, m.p. $>230{ }^{\circ} \mathrm{C}$ (文献 $[15,16]$, 收率 46.6\%, m.p. $>200{ }^{\circ} \mathrm{C}$ ).

\subsection{6-乙酰氧基-7-甲氧基喹唑啉-4-酮(4)的合成}

参考文献 $[15,16]$ 合成，白色固体，收率 94.5\%. m.p. $>230{ }^{\circ} \mathrm{C}$ (文献 $[15,16]$, 收率 $95.6 \%$, m.p. $>200{ }^{\circ} \mathrm{C}$ ).

\subsection{6-乙酰氧基-7-甲氧基-4-(3-氯-4-氟苯胺基)喹唑啉} (5)的合成

参考文献 $[15,16]$ 合成，白色固体，收率 53.0\%. m.p. $>230{ }^{\circ} \mathrm{C}$ (文献 $[15,16]$, 收率 $52.1 \%$, m.p. $>270{ }^{\circ} \mathrm{C}$ ).

\subsection{4-(3-氯-4-氟苯胺基)-6-羟基-7-甲氧基喹唑啉(6)的} 合成

参考文献 $[15,16]$ 合成，白色粉末，收率 95.0\%. m.p. $>200{ }^{\circ} \mathrm{C}$ (文献 $[15,16]$, 收率 95.2\%. m.p.>200 ${ }^{\circ} \mathrm{C}$ ). ${ }^{1} \mathrm{H}$ NMR (400 MHz, DMSO-d $)_{6} \delta 9.69(\mathrm{~s}, 1 \mathrm{H}), 9.47$ (s, 1H), $8.48(\mathrm{~s}, 1 \mathrm{H}), 8.22(\mathrm{dd}, J=6.9,2.6 \mathrm{~Hz}, 1 \mathrm{H}), 7.84$ (dd, $J=$ 9.0, 4.3 Hz, 1H), 7.78 (s, 1H), 7.41 (t, $J=9.1 \mathrm{~Hz}, 1 \mathrm{H}), 7.22$ (s, 1H), 3.98 (s, 3H); IR (KBr) v: 3384, 2935, 2469, 1897, $1586,1519,1417,1215,1003,933,649,507 \mathrm{~cm}^{-1}$.

\section{7 吉非替尼衍生物 $7 a \sim 7 d$ 的合成}

向 $100 \mathrm{~mL}$ 三口瓶中, 依次加入 4-(3-氯-4-氟苯 胺)-7-甲氧基-喹唑啉-6 醇(0.5 g, $1.56 \mathrm{mmol})$, 取代对甲 苯磺酸酯(3.9 mmol), $N, N$-二甲基甲酰胺 $20 \mathrm{~mL}$, 无水 $\mathrm{K}_{2} \mathrm{CO}_{3}(1.07 \mathrm{~g}, 7.8 \mathrm{mmol})$, 少量 $\mathrm{KI}$. 搅拌并加热至 $75{ }^{\circ} \mathrm{C}$ 反应 $3 \mathrm{~h}$, TLC 跟踪至反应完成, 冷却至室温, 倒 入 $100 \mathrm{~g}$ 冰水中, 搅拌有固体析出, 抽滤得到固体粗品, $[V($ 乙酸乙酯 $): V($ 石油醚 $)=3 \sim 5: 1$ 重结晶得到化合 物 $\mathbf{7 a} \sim \mathbf{7 d}$.

4-(3-氯-4-氟苯胺基)-7-甲氧基-6-(甲氧乙氧基)喹啉 (7a): 白色固体，收率 57\%. m.p. 115.2 117.0 ${ }^{\circ} \mathrm{C} ;{ }^{1} \mathrm{H}$ NMR (400 MHz, $\left.\mathrm{CDCl}_{3}\right) \delta: 8.66(\mathrm{~s}, 1 \mathrm{H}), 7.90(\mathrm{dd}, J=$ 6.5, 2.7 Hz, 1H), 7.52 (dd, $J=8.9,4.0 \mathrm{~Hz}, 1 \mathrm{H}), 7.24$ (s, $1 \mathrm{H}), 7.18$ (t, $J=8.7 \mathrm{~Hz}, 1 \mathrm{H}), 7.14$ (s, 1H), 7.08 (s, 1H), $4.30 \sim 4.36(\mathrm{~m}, 2 \mathrm{H}), 4.00(\mathrm{~s}, 3 \mathrm{H}), 3.87(\mathrm{dd}, J=5.4,4.0$ $\mathrm{Hz}, 2 \mathrm{H}), 3.49$ (s, 3H); ${ }^{13} \mathrm{C}$ NMR (100 MHz, $\left.\mathrm{CDCl}_{3}\right) \delta$ : $156.1,155.4,153.6,149.0,147.8,135.3,135.2,124.0$, $121.5,116.5,116.0,109.2,108.2,101.4,69.1,68.0,59.4$, 56.2; IR (KBr) v: 3346, 2929, 2188, 1640, 1576, 1502,1425, 1223, 1072, 934, 697, $546 \mathrm{~cm}^{-1}$; HRMS (ESI-MS) calcd for $\mathrm{C}_{18} \mathrm{H}_{17} \mathrm{ClFN}_{3} \mathrm{O}_{3}[\mathrm{M}+\mathrm{H}]^{+}$378.0992, found 378.0996 .

4-(3-氯-4-氟苯胺基)-7-甲氧基-6-(甲氧乙氧乙氧基) 喹啉(7b): 类白色固体, 收率 68\%. m.p. 58.5 59.5 ${ }^{\circ} \mathrm{C}$; ${ }^{1} \mathrm{H}$ NMR (400 MHz, $\left.\mathrm{CDCl}_{3}\right) \delta: 8.64(\mathrm{~s}, 1 \mathrm{H}), 7.91$ (dd, $J=$ 6.6, $2.6 \mathrm{~Hz}, 1 \mathrm{H}), 7.68(\mathrm{~s}, 1 \mathrm{H}), 7.58(\mathrm{dd}, J=8.9,4.1 \mathrm{~Hz}$, $1 \mathrm{H}), 7.53(\mathrm{~s}, 1 \mathrm{H}), 7.23(\mathrm{~s}, 1 \mathrm{H}), 7.16(\mathrm{t}, J=8.8 \mathrm{~Hz}, 1 \mathrm{H})$, $4.34 \sim 4.40(\mathrm{~m}, 2 \mathrm{H}), 3.99(\mathrm{~s}, 3 \mathrm{H}), 3.86 \sim 3.95(\mathrm{~m}, 2 \mathrm{H})$, $3.68 \sim 3.80(\mathrm{~m}, 2 \mathrm{H}), 3.60 \sim 3.68(\mathrm{~m}, 2 \mathrm{H}), 3.32(\mathrm{~s}, 3 \mathrm{H}) ;{ }^{13} \mathrm{C}$ NMR $\left(100 \mathrm{MHz}, \mathrm{CDCl}_{3}\right) \delta: 156.6,155.8,155.2,153.5$, $148.6,147.5,135.8,124.2,120.7,116.3,109.1,107.5$, 103.5, 77.1, 71.8, 70.3, 69.4, 58.7, 56.1; IR (KBr) v: 3328, 3127, 2936, 2883, 2195, 1633, 1576, 1502, 1425, 1344, 1206, 1125, 934, 853, 690, $546 \mathrm{~cm}^{-1}$; HRMS (ESI-MS) calcd for $\mathrm{C}_{20} \mathrm{H}_{21} \mathrm{ClFN}_{3} \mathrm{O}_{4}[\mathrm{M}+\mathrm{H}]^{+}$422.1285, found 422.1284 .

4-(3-氯-4-氟苯胺基)-7-甲氧基-6-(甲氧乙氧乙氧乙 氧基)喹啉(7c)：白色固体，收率 75\%. m.p. 113.8 $113.9{ }^{\circ} \mathrm{C} ;{ }^{1} \mathrm{H}$ NMR (400 MHz, $\left.\mathrm{CDCl}_{3}\right) \delta: 8.62(\mathrm{~s}, 1 \mathrm{H})$, $8.28(\mathrm{~s}, 1 \mathrm{H}), 7.92(\mathrm{dd}, J=6.6,2.5 \mathrm{~Hz}, 1 \mathrm{H}), 7.60 \sim 7.68(\mathrm{~m}$, $1 \mathrm{H}), 7.51(\mathrm{~s}, 1 \mathrm{H}), 7.14(\mathrm{dd}, J=11.2,6.3 \mathrm{~Hz}, 2 \mathrm{H}), 4.20 \sim$ $4.28(\mathrm{~m}, 2 \mathrm{H}), 3.90(\mathrm{~s}, 3 \mathrm{H}), 3.82 \sim 3.92(\mathrm{~m}, 2 \mathrm{H}), 3.70(\mathrm{dd}$, $J=10.7,5.4 \mathrm{~Hz}, 4 \mathrm{H}), 3.62(\mathrm{dd}, J=5.5,3.4 \mathrm{~Hz}, 2 \mathrm{H}), 3.50$ $(\mathrm{dd}, J=5.5,3.4 \mathrm{~Hz}, 2 \mathrm{H}), 3.26(\mathrm{~s}, 3 \mathrm{H}) ;{ }^{\mathrm{I}} \mathrm{C} \mathrm{NMR}(100$ $\left.\mathrm{MHz} \mathrm{CDCl}_{3}\right) \delta: 156.8,155.8,153.5,148.5,147.5,135.9$, 
$124.5,120.7,116.3,109.2,107.4,103.2,77.3,76.8,70.6$, 70.3, 68.7, 58.8, 56.0; IR (KBr) v: 3326, 3094, 2878, 1621, 1503, 1421, 1214, 1101, 1003, 849, 782, 694, $540 \mathrm{~cm}^{-1}$; HRMS (ESI-MS) calcd for $\mathrm{C}_{22} \mathrm{H}_{25} \mathrm{ClFN}_{3} \mathrm{O}_{5}[\mathrm{M}+\mathrm{H}]^{+}$ 466.1547, found 466.1541.

4-(3-氯-4-氟苯胺基)-7-甲氧基-6-(甲氧乙氧乙氧乙 氧乙氧基)喹啉(7d)：白色固体，收率 75\%. m.p. 64.8 $65.4{ }^{\circ} \mathrm{C} ;{ }^{1} \mathrm{H}$ NMR (400 MHz, $\mathrm{CDCl}_{3}$ ) $\delta: 8.61$ (s, 2H), 7.92 $(\mathrm{dd}, J=6.6,2.6 \mathrm{~Hz}, 1 \mathrm{H}), 7.67(\mathrm{~m}, 2 \mathrm{H}), 7.15(\mathrm{dd}, J=11.8$, $5.7 \mathrm{~Hz}, 2 \mathrm{H}), 4.35(\mathrm{t}, J=5.0 \mathrm{~Hz}, 2 \mathrm{H}), 3.92(\mathrm{~s}, 3 \mathrm{H}), 3.81 \sim$ $3.90(\mathrm{~m}, 2 \mathrm{H}), 3.70(\mathrm{dd}, J=6.1,2.5 \mathrm{~Hz}, 2 \mathrm{H}), 3.62(\mathrm{~m}, 6 \mathrm{H})$, 3.55 (dd, $J=5.6,3.4 \mathrm{~Hz}, 2 \mathrm{H}), 3.45$ (dd, $J=5.6,3.4 \mathrm{~Hz}$, 2H), $3.23(\mathrm{~s}, 3 \mathrm{H}) ;{ }^{\mathrm{I}} \mathrm{C} \mathrm{NMR}\left(100 \mathrm{MHz}, \mathrm{CDCl}_{3}\right) \delta: 156.8$, $155.8,155.0,153.5,148.4,147.4,136.0,124.5,120.5$, 116.2, 109.2, 107.4, 103.5, 77.1, 71.7, 70.4, 69.8, 58.8, 56.1; IR (KBr) v: 3471, 3337, 3115, 2883, 1822, 1458, 1431, 1343, 1220, 1116, 931, 849, 787, 689, $545 \mathrm{~cm}^{-1}$; HRMS (ESI-MS) calcd for $\mathrm{C}_{24} \mathrm{H}_{29} \mathrm{ClFN}_{3} \mathrm{O}_{6}[\mathrm{M}+\mathrm{H}]^{+}$ 510.1799 , found 510.1798 .

\section{8 吉非替尼衍生物 $8 \mathrm{a} \sim 80$ 的合成}

向 $100 \mathrm{~mL}$ 的三口瓶中, 依次加入二氯甲烷 $20 \mathrm{~mL}$, 胺 $(1.87 \mathrm{mmol})$, 三乙胺 $0.31 \mathrm{~g}(2.99 \mathrm{mmol})$, 降温至 $0{ }^{\circ} \mathrm{C}$, 保持此温度缓慢滴加氯乙酰氯 $0.25 \mathrm{~g}(2.24 \mathrm{mmol})$ 的二 氯甲烷 $(10 \mathrm{~mL})$ 溶液. 滴毕升至室温反应 $5 \sim 6 \mathrm{~h}$, TLC 跟 踪, 原料点消失, 停止反应, 倒入 $20 \mathrm{~mL}$ 水中, 分出有 机相, 水洗 2 次 $(10 \mathrm{~mL} \times 2)$, 无水硫酸钠干燥, 过滤, 蒸 馏除去溶剂得固体残余物, 干燥后直接用于下一步反 应.

将上一步所得固体残余物加入 $100 \mathrm{~mL}$ 的三口瓶中, 依次加入 4-(3-氯-4-氟苯胺)-7-甲氧基-喹唑啉-6 醇 $0.5 \mathrm{~g}$ (1.56 mmol), $N, N$-二甲基甲酰胺 $20 \mathrm{~mL}$, 无水 $\mathrm{K}_{2} \mathrm{CO}_{3}$ $0.52 \mathrm{~g}$ (3.74 mmol), KI 催化量. 在 $80{ }^{\circ} \mathrm{C}$ 反应 $6 \mathrm{~h}, \mathrm{TLC}$ 跟 踪, 原料点消失, 停止反应降至室温, 倒入水中, 有固 体析出, 过滤, 固体粗产物经 $[V($ 甲醇 $): V($ 乙酸乙酯 $)=$ 5 8: 1)重结晶得化合物 $\mathbf{8 a} \sim \mathbf{8 0}$.

4-(3-氯-4-氟苯胺基)-7-甲氧基-6-(氧代乙酰苯胺基) 喹啉(8a): 白色固体, 产率 74.3\%. m.p. 267.1 269.3 ${ }^{\circ} \mathrm{C}$; ${ }^{1} \mathrm{H}$ NMR (400 MHz, DMSO-d $\left.d_{6}\right) \delta: 10.06$ (s, 1H), 9.58 (s, $1 \mathrm{H}), 8.53$ (s, 1H), 8.12 (dd, $J=6.8,2.6 \mathrm{~Hz}, 1 \mathrm{H}), 7.95$ (s, 1H), 7.77 (dd, $J=9.0,4.3 \mathrm{~Hz}, 1 \mathrm{H}), 7.66(\mathrm{~d}, J=7.7 \mathrm{~Hz}$, 2H), 7.45 (t, $J=9.1 \mathrm{~Hz}, 1 \mathrm{H}), 7.33$ (dd, $J=20.3,12.2 \mathrm{~Hz}$, $3 \mathrm{H}), 7.10(\mathrm{t}, J=7.4 \mathrm{~Hz}, 1 \mathrm{H}), 4.89(\mathrm{~s}, 2 \mathrm{H}), 4.00(\mathrm{~s}, 3 \mathrm{H}) ;{ }^{13} \mathrm{C}$ NMR (100 MHz, DMSO- $\left.d_{6}\right) \delta: 166.3,156.7,155.0$, $154.90,153.5,152.5,148.0,138.7,137.2,129.3,124.3$, $124.0,122.8,120.1,119.3,116.9,109.1,108.1,104.7$,
69.1, 56.5; IR (KBr) v: 3394, 3195, 3004, 1673, 1631, 1504, 1434, 1230, 1140, 997, 842, 752, $557 \mathrm{~cm}^{-1}$; HRMS (ESI-MS) calcd for $\mathrm{C}_{23} \mathrm{H}_{18} \mathrm{ClFN}_{4} \mathrm{O}_{3}[\mathrm{M}+\mathrm{H}]^{+}$453.1131, found 453.1132 .

4-(3-氯-4-氟苯胺基)-7-甲氧基-6-(氧代乙酰- $\alpha$-苯乙 胺基)喹啉 $(8 \mathbf{b})$ : 白色固体, 产率 73.4\%. m.p. 235.6 $237.8{ }^{\circ} \mathrm{C} ;{ }^{1} \mathrm{H}$ NMR (400 MHz, DMSO- $\left.d_{6}\right) \delta: 9.51(\mathrm{~s}, 1 \mathrm{H})$, 8.52 (s, 1H), 8.32 (d, $J=7.9 \mathrm{~Hz}, 1 \mathrm{H}), 8.10$ (d, $J=6.7 \mathrm{~Hz}$, 1H), 7.87 (s, 1H), 7.78 (dd, $J=8.3,3.3 \mathrm{~Hz}, 1 \mathrm{H}), 7.45$ (t, $J=9.1 \mathrm{~Hz}, 1 \mathrm{H}), 7.38 \sim 7.17(\mathrm{~m}, 6 \mathrm{H}), 5.03(\mathrm{dd}, J=14.3$, $7.1 \mathrm{~Hz}, 1 \mathrm{H}), 4.73$ (s, 2H), 3.95 (s, 3H), 1.43 (d, $J=6.9 \mathrm{~Hz}$, $3 \mathrm{H}) ;{ }^{13} \mathrm{C}$ NMR (100 MHz, DMSO- $\left.d_{6}\right) \delta: 166.7,156.6$, $153.5,152.4,147.9144 .5,137.2,128.7,119.4,119.2$, 117.1, 116.9, 109.1, 108.0, 104.7, 68.9, 56.4, 48.4, 22.5; IR (KBr) v: 3369, 3219, 2979, 1626, 1504, 1428, 1209, 1075, $1002,857,701,606,548 \mathrm{~cm}^{-1}$; HRMS (ESI-MS) calcd for $\mathrm{C}_{25} \mathrm{H}_{22} \mathrm{ClFN}_{4} \mathrm{O}_{3}[\mathrm{M}+\mathrm{H}]^{+}$481.1434, found 481.1438 .

4-(3-氯-4-氟苯胺基)-7-甲氧基-6-(氧代乙酰苯乙胺 基)喹啉 (8c): 白色固体，产率 75.6\%. m.p. 226.7 $227.8{ }^{\circ} \mathrm{C} ;{ }^{1} \mathrm{H}$ NMR (400 MHz, DMSO- $\left.d_{6}\right) \delta$ : $9.56(\mathrm{~s}, 1 \mathrm{H})$, $8.53(\mathrm{~s}, 1 \mathrm{H}), 8.10(\mathrm{dd}, J=6.8,2.4 \mathrm{~Hz}, 1 \mathrm{H}), 7.92 \sim 7.85(\mathrm{~m}$, 2H), $7.81 \sim 7.74(\mathrm{~m}, 1 \mathrm{H}), 7.45(\mathrm{t}, J=9.1 \mathrm{~Hz}, 1 \mathrm{H}), 7.30 \sim$ $7.15(\mathrm{~m}, 6 \mathrm{H}), 4.67$ (s, 2H), $3.96(\mathrm{~s}, 3 \mathrm{H}), 3.43$ (dd, $J=13.5$, $6.7 \mathrm{~Hz}, 2 \mathrm{H}), 2.79$ (t, $J=7.2 \mathrm{~Hz}, 2 \mathrm{H}) ;{ }^{13} \mathrm{C} \mathrm{NMR}(100 \mathrm{MHz}$, DMSO- $\left.d_{6}\right) \delta: 167.5,154.9,153.5,152.5,147.6,139.1$, $137.2,129.1,122.8,119.3,117.1,116.9,109.0,108.0$, 104.3, 68.6, 56.5, 35.5; IR (KBr) v: 3395, 3326, 3031, 2922, 1668, 1625, 1500, 1428, 1215, 1144, 1007, 881, 699, $547 \mathrm{~cm}^{-1}$; HRMS (ESI-MS) calcd for $\mathrm{C}_{25} \mathrm{H}_{22} \mathrm{ClFN}_{4} \mathrm{O}_{3}$ $[\mathrm{M}+\mathrm{H}]^{+}$481.1434, found 481.1437 .

4-(3-氯-4-氟苯胺基)-7-甲氧基-6-(氧代乙酰-4-氯苯 胺基)喹啉(8d): 白色固体，产率 69.7\%. m.p. 244.3 $245.8{ }^{\circ} \mathrm{C}$; ${ }^{1} \mathrm{H}$ NMR (400 MHz, DMSO- $\left.d_{6}\right) \delta$ : 10.22 (s, $1 \mathrm{H}), 9.56(\mathrm{~s}, 1 \mathrm{H}), 8.53(\mathrm{~s}, 1 \mathrm{H}), 8.11(\mathrm{dd}, J=6.8,2.6 \mathrm{~Hz}$, $1 \mathrm{H}), 7.93(\mathrm{~s}, 1 \mathrm{H}), 7.82 \sim 7.66(\mathrm{~m}, 3 \mathrm{H}), 7.50 \sim 7.37(\mathrm{~m}$, $3 \mathrm{H}), 7.28(\mathrm{~s}, 1 \mathrm{H}), 4.89(\mathrm{~s}, 2 \mathrm{H}), 3.99(\mathrm{~s}, 3 \mathrm{H}) ;{ }^{13} \mathrm{C} \mathrm{NMR}$ $\left(100 \mathrm{MHz}, \mathrm{DMSO}-d_{6}\right) \delta: 166.5,155.1,153.5,147.9,137.8$, $137.2,129.2,127.9,119.4,116.9,109.1,108.2,104.8$, 69.0, 49.1; IR (KBr) v: 3368, 3127, 2915, 2802, 1703, 1504, 1429, 1340, 1233, 1147, 1025, 933, 837, 674, 558 $\mathrm{cm}^{-1}$; HRMS (ESI-MS) calcd for $\mathrm{C}_{23} \mathrm{H}_{17} \mathrm{Cl}_{2} \mathrm{FN}_{4} \mathrm{O}_{3}[\mathrm{M}+$ $\mathrm{H}]^{+}$487.0732, found 487.0738.

4-(3-氯-4-氟苯胺基)-7-甲氧基-6-(氧代乙酰-4-氟苯 胺基)喹啉(8e): 浅黄色固体, 产率 76.4\%. m.p. 244.3 $245.8{ }^{\circ} \mathrm{C}$; ${ }^{1} \mathrm{H}$ NMR (400 MHz, DMSO- $d_{6}$ ) $\delta$ : 10.12 (s, 
1H), 9.56 (s, 1H), $8.52(\mathrm{~s}, 1 \mathrm{H}), 8.10(\mathrm{dd}, J=6.8,2.6 \mathrm{~Hz}$, 1H), $7.93(\mathrm{~s}, 1 \mathrm{H}), 7.76(\mathrm{dd}, J=9.0,4.3,2.7 \mathrm{~Hz}, 1 \mathrm{H})$, $7.70 \sim 7.65(\mathrm{~m}, 2 \mathrm{H}), 7.45(\mathrm{t}, J=9.1 \mathrm{~Hz}, 1 \mathrm{H}), 7.28(\mathrm{~s}, 1 \mathrm{H})$, $7.18(\mathrm{t}, J=8.9 \mathrm{~Hz}, 2 \mathrm{H}), 4.87(\mathrm{~s}, 2 \mathrm{H}), 3.99(\mathrm{~s}, 3 \mathrm{H}) ;{ }^{13} \mathrm{C}$ NMR $\left(100 \mathrm{MHz}\right.$, DMSO- $\left.d_{6}\right) \delta: 166.3,159.9,157.6,155.1$, $152.5,148.0,137.1,135.1,124.0,116.9,115.7,109.1$, 108.1, 104.8, 69.0, 56.5; IR (KBr) v: 3353, 3004, 2380, 1674, 1629, 1508, 1433, 1343, 1231, 1141, 999, 835, 556 $\mathrm{cm}^{-1}$; HRMS (ESI-MS) calcd for $\mathrm{C}_{23} \mathrm{H}_{17} \mathrm{ClF}_{2} \mathrm{~N}_{4} \mathrm{O}_{3}[\mathrm{M}+$ $\mathrm{H}]^{+}$471.1023, found 471.1029

4-(3-氯-4-氟苯胺基)-7-甲氧基-6-(氧代乙酰-4-甲基 苯胺基)喹啉(8f): 白色固体, 产率 75.3\%. m.p. 260.2 $261.7{ }^{\circ} \mathrm{C} ;{ }^{1} \mathrm{H}$ NMR (400 MHz, DMSO- $\left.d_{6}\right) \delta: 9.94$ (s, $\left.1 \mathrm{H}\right)$, $9.55(\mathrm{~s}, 1 \mathrm{H}), 8.52(\mathrm{~s}, 1 \mathrm{H}), 8.11(\mathrm{dd}, J=6.8,2.5 \mathrm{~Hz}, 1 \mathrm{H})$, $7.93(\mathrm{~s}, 1 \mathrm{H}), 7.76$ (dd, $J=8.9,4.1,2.8 \mathrm{~Hz}, 1 \mathrm{H}), 7.53(\mathrm{~d}$, $J=8.2 \mathrm{~Hz}, 2 \mathrm{H}), 7.44$ (t, $J=9.1 \mathrm{~Hz}, 1 \mathrm{H}), 7.27$ (s, 1H), 7.14 (d, $J=8.2 \mathrm{~Hz}, 2 \mathrm{H}), 4.85$ (s, 2H), 3.99 (s, 3H), 2.26 (s, 3H); ${ }^{13} \mathrm{C}$ NMR $\left(100 \mathrm{MHz}\right.$, DMSO- $\left.d_{6}\right) \delta: 166.1,156.1,154.9$, $153.5,147.9,137.2,136.2,133.2,129.7,119.4,117.0$, 109.1, 108.1, 104.6, 69.1, 56.5, 20.9; IR (KBr) v: 3351, 3031, 2924, 1677, 1500, 1428, 1215, 1141, 1004, 812, 633, $550 \mathrm{~cm}^{-1}$; HRMS (ESI-MS) calcd for $\mathrm{C}_{24} \mathrm{H}_{20} \mathrm{ClFN}_{4} \mathrm{O}_{3}$ $[\mathrm{M}+\mathrm{H}]^{+}$467.1288, found 467.1289.

4-(3-氯-4-氟苯胺基)-7-甲氧基-6-(氧代乙酰-4-三氟 甲氧基苯胺基)喹啉 $(8 \mathrm{~g})$ ：白色固体，产率 78.4\%. m.p. 263 $264{ }^{\circ} \mathrm{C} ;{ }^{1} \mathrm{H}$ NMR (400 MHz, DMSO- $d_{6}$ ) $\delta: 10.30$ (s, 1H), 9.56 (s, 1H), 8.53 (s, 1H), 8.11 (dd, $J=6.8,2.6 \mathrm{~Hz}$, 1H), $7.93(\mathrm{~s}, 1 \mathrm{H}), 7.83 \sim 7.70(\mathrm{~m}, 3 \mathrm{H}), 7.46(\mathrm{~d}, J=9.1 \mathrm{~Hz}$, 1H), $7.42 \sim 7.31(\mathrm{~m}, 2 \mathrm{H}), 7.28(\mathrm{~s}, 1 \mathrm{H}), 4.90(\mathrm{~s}, 2 \mathrm{H}), 4.00$ $(\mathrm{s}, 3 \mathrm{H}),{ }^{13} \mathrm{C}$ NMR (100 MHz, DMSO- $\left.d_{6}\right) \delta: 166.6,155.1$, $153.5,152.5,144.4,137.1,122.9,121.5,119.2,116.9$, 109.1, 108.1, 104.8, 69.0, 56.5; IR (KBr) v: 3668, 3366, 2938, 1676, 1631, 1506, 1432, 1343, 1211, 997, 934, 842, $661,557 \mathrm{~cm}^{-1}$; HRMS (ESI-MS) calcd for $\mathrm{C}_{24} \mathrm{H}_{17} \mathrm{Cl}$ $\mathrm{F}_{4} \mathrm{~N}_{4} \mathrm{O}_{4}[\mathrm{M}+\mathrm{H}]^{+}$537.0944, found 537.0946.

4-(3-氯-4-氟苯胺基)-7-甲氧基-6-(氧代乙酰-3-乙炔 基苯胺基)喹啉(8h): 浅黄色固体, 产率 78.7\%. m.p. $272.3 \sim 274.7{ }^{\circ} \mathrm{C} ;{ }^{1} \mathrm{H}$ NMR (400 MHz, DMSO- $d_{6}$ ) $\delta$ : 10.20 (s, 2H), 9.57 (s, 1H), 8.53 (s, 1H), 8.11 (dd, $J=6.8$, $2.6 \mathrm{~Hz}, 1 \mathrm{H}), 7.93$ (s, 1H), 7.86 (s, 1H), 7.76 (dd, $J=8.9$, $4.2,2.7 \mathrm{~Hz}, 1 \mathrm{H}), 7.65(\mathrm{~d}, J=9.3 \mathrm{~Hz}, 1 \mathrm{H}), 7.41$ (dd, $J=$ $15.9,8.6 \mathrm{~Hz}, 2 \mathrm{H}), 7.28(\mathrm{~s}, 1 \mathrm{H}), 7.21(\mathrm{~d}, J=7.6 \mathrm{~Hz}, 1 \mathrm{H})$, 4.89 (s, 2H), 4.19 (s, 1H), 4.00 (s, 3H); ${ }^{13} \mathrm{C}$ NMR (101 MHz, DMSO- $\left.d_{6}\right) \delta$ : $166.7,156.7,155.1,153.5,148.0$, $139.0,137.1,124.9,122.6,119.4,116.9,109.1,108.1$,
104.7, 83.7, 81.2, 69.0; IR (KBr) v: 3388, 3296, 2939, 2828, 1706, 1502, 1430, 1235, 1143, 1001, 862, 790, 688, $557 \mathrm{~cm}^{-1}$; HRMS (ESI-MS) calcd for $\mathrm{C}_{25} \mathrm{H}_{18} \mathrm{ClFN}_{4} \mathrm{O}_{3}$ $[\mathrm{M}+\mathrm{H}]^{+}$477.1121, found 477.1125.

4-(3-氯-4-氟苯胺基)-7-甲氧基-6-(氧代乙酰-3,4-二 氯苯胺基)喹啉 (8i): 白色固体, 产率 71.7\%. m.p. 243 $244{ }^{\circ} \mathrm{C} ;{ }^{1} \mathrm{H}$ NMR (400 MHz, DMSO- $\left.d_{6}\right) \delta$ : $10.41(\mathrm{~s}, 1 \mathrm{H})$, $9.56(\mathrm{~s}, 1 \mathrm{H}), 8.53(\mathrm{~s}, 1 \mathrm{H}), 8.17 \sim 8.02(\mathrm{~m}, 2 \mathrm{H}), 7.92(\mathrm{~s}$, $1 \mathrm{H}), 7.75(\mathrm{dd}, J=9.0,4.3 \mathrm{~Hz}, 1 \mathrm{H}), 7.61(\mathrm{~s}, 2 \mathrm{H}), 7.45(\mathrm{t}$, $J=9.1 \mathrm{~Hz}, 1 \mathrm{H}), 7.29$ (s, 1H), 4.91 (s, 2H), 4.00 (s, 3H); ${ }^{13} \mathrm{C}$ NMR (100 MHz, DMSO- $\left.d_{6}\right) \delta: 167.0,155.1,153.5$, $152.5,147.9,138.9,137.1,131.2,123.0,119.4,116.9$, 109.0, 108.2, 104.9, 68.9, 56.5; IR (KBr) v: 3374, 3062, 2932, 1686, 1632, 1585, 1500, 1433, 1338, 1236, 1089, 1007, 852, 683, $553 \mathrm{~cm}^{-1}$; HRMS (ESI-MS) calcd for $\mathrm{C}_{23} \mathrm{H}_{16} \mathrm{Cl}_{3} \mathrm{FN}_{4} \mathrm{O}_{3} \quad[\mathrm{M}+\mathrm{H}]^{+}$521.0354, found 521.0352.

4-(3-氯-4-氟苯胺基)-7-甲氧基-6-(氧代乙酰-3-氟-4氯苯胺基)喹啉 $(8 \mathbf{j})$ : 白色固体, 产率 $77.8 \%$. m.p. $253.1 \sim 255.3{ }^{\circ} \mathrm{C} ;{ }^{1} \mathrm{H}$ NMR (400 MHz, DMSO- $d_{6}$ ) $\delta: 10.33$ (s, 1H), 9.57 (s, 1H), 8.53 (s, 1H), 8.10 (dd, $J=6.8,2.6 \mathrm{~Hz}$, $1 \mathrm{H}), 7.98(\mathrm{dd}, J=6.8,2.5 \mathrm{~Hz}, 1 \mathrm{H}), 7.92(\mathrm{~s}, 1 \mathrm{H}), 7.75$ (dd, $J=8.9,4.1,2.8 \mathrm{~Hz}, 1 \mathrm{H}), 7.58(\mathrm{dd}, J=8.9,4.1 \mathrm{~Hz}, 1 \mathrm{H})$, 7.43 (dd, $J=16.5,9.1 \mathrm{~Hz}, 2 \mathrm{H}), 7.28$ (s, 1H), 4.89 (s, 2H), 3.99 (s, 3H); ${ }^{13} \mathrm{C}$ NMR (100 MHz, DMSO- $\left.d_{6}\right) \delta: 166.8$, $155.1,153.6,152.5,147.9,137.1,136.0,121.7,119.6$, $117.6,116.9,109.4,108.2,104.8,68.9,56.5$; IR (KBr) $v$ : $3376,3343,1683,1581,1501,1428,1262,1214,1147$, $1007,855,707,544 \mathrm{~cm}^{-1}$; HRMS (ESI-MS) calcd for $\mathrm{C}_{23} \mathrm{H}_{16} \mathrm{Cl}_{2} \mathrm{~F}_{2} \mathrm{~N}_{4} \mathrm{O}_{3}[\mathrm{M}+\mathrm{H}]^{+}$505.0648, found 505.0645.

4-(3-氯-4-氟苯胺基)-7-甲氧基-6-(氧代乙酰-2,4-二 甲氧基嘧啶胺基)喹啉 $(8 \mathrm{k})$ ：白色固体，产率 71.6\%. m.p. $249.5 \sim 252.1{ }^{\circ} \mathrm{C} ;{ }^{1} \mathrm{H}$ NMR $\left(400 \mathrm{MHz}\right.$, DMSO- $\left.d_{6}\right) \delta: 10.63$ (s, 1H), 9.55 (s, 1H), 8.52 (s, 1H), 8.09 (dd, $J=6.8,2.6 \mathrm{~Hz}$, 1H), $7.88(\mathrm{~s}, 1 \mathrm{H}), 7.74(\mathrm{dd}, J=9.0,4.3 \mathrm{~Hz}, 1 \mathrm{H}), 7.45$ (t, $J=9.1 \mathrm{~Hz}, 1 \mathrm{H}), 7.28(\mathrm{~s}, 1 \mathrm{H}), 7.07(\mathrm{~s}, 1 \mathrm{H}), 5.00(\mathrm{~s}, 2 \mathrm{H})$, $4.00(\mathrm{~s}, 3 \mathrm{H}), 3.90(\mathrm{~d}, J=7.9 \mathrm{~Hz}, 6 \mathrm{H}) ;{ }^{13} \mathrm{C}$ NMR $(100 \mathrm{MHz}$, DMSO- $\left.d_{6}\right) \delta: 173.0,164.9,154.9,152.6,147.8,137.1$, 124.3, 119.2, 117.2, 116.9, 109.0, 108.2, 104.6, 88.1, 68.4, 56.5, 54.9, 54.5; IR (KBr) v: 3486, 3376, 2945, 1700, $1584,1503,1429,1359,1233,1100,1000,829,685,550$ $\mathrm{cm}^{-1}$; HRMS (ESI-MS) calcd for $\mathrm{C}_{23} \mathrm{H}_{20} \mathrm{ClFN}_{6} \mathrm{O}_{5}[\mathrm{M}+$ $\mathrm{H}]^{+}$515.1232, found 515.1238.

4-(3-氯-4-氟苯胺基)-7-甲氧基-6-(氧代乙酰-环丙胺 基)喹啉(81): 浅黄色固体, 产率 68.8\%. m.p. 263.9 $265.3{ }^{\circ} \mathrm{C} ;{ }^{1} \mathrm{H}$ NMR (400 MHz, DMSO- $\left.d_{6}\right) \delta$ : 9.54 (s, $1 \mathrm{H}$ ), 
8.52 (s, $1 \mathrm{H}), 8.12$ (dd, $J=6.8,2.6 \mathrm{~Hz}, 1 \mathrm{H}), 7.98$ (d, $J=3.6$ $\mathrm{Hz}, 1 \mathrm{H}), 7.86$ (s, 1H), 7.77 (dd, $J=9.0,4.3 \mathrm{~Hz}, 1 \mathrm{H}), 7.46$ (t, $J=9.1 \mathrm{~Hz}, 1 \mathrm{H}), 7.25(\mathrm{~s}, 1 \mathrm{H}), 4.63(\mathrm{~s}, 2 \mathrm{H}), 3.97(\mathrm{~s}, 3 \mathrm{H})$, $2.74(\mathrm{dd}, J=7.3,3.9 \mathrm{~Hz}, 1 \mathrm{H}), 0.67(\mathrm{dd}, J=7.0,4.8 \mathrm{~Hz}$, $2 \mathrm{H}), 0.58 \sim 0.43(\mathrm{~m}, 2 \mathrm{H}) ;{ }^{13} \mathrm{C}$ NMR (100 MHz, DMSO- $\left.d_{6}\right)$ $\delta: 168.6,155.0,153.5,152.5,147.9,137.2,122.8,119.3$, 117.2, 116.9, 109.1, 108.1, 104.6, 68.8, 56.5, 22.7, 6.2; IR (KBr) $v$ : 3405, 3285, 1640, 1532, 1500, 1429, 1213, 1138, 996, 843, 692, $545 \mathrm{~cm}^{-1}$; HRMS (ESI-MS) calcd for $\mathrm{C}_{20} \mathrm{H}_{18} \mathrm{ClFN}_{4} \mathrm{O}_{3}[\mathrm{M}+\mathrm{H}]^{+}$417.1171, found 417.1177.

4-(3-氯-4-氟苯胺基)-7- 甲氧基-6-[氧代乙酰胺 基-( $L$ )-丙胺酸甲酯]喹啉 $(8 \mathrm{~m})$ : 白色固体, 产率 $65.7 \%$. m.p. $213.3 \sim 215.1{ }^{\circ} \mathrm{C} ;{ }^{1} \mathrm{H}$ NMR (400 MHz, DMSO- $\left.d_{6}\right) \delta$ : 9.49 (s, 1H), 8.53 (s, 1H), 8.34 (d, $J=7.2 \mathrm{~Hz}, 1 \mathrm{H}), 8.12$ (dd, $J=6.8,2.6 \mathrm{~Hz}, 1 \mathrm{H}), 7.87$ (s, 1H), 7.77 (dd, $J=9.0,4.2$ $\mathrm{Hz}, 1 \mathrm{H}), 7.45(\mathrm{t}, \quad J=9.1 \mathrm{~Hz}, 1 \mathrm{H}), 7.26(\mathrm{~s}, 1 \mathrm{H}), 4.85 \sim$ 4.64 (m, 2H), 4.43 (p, J=7.2 Hz, 1H), 3.98 (s, 3H), 3.63 $(\mathrm{s}, 3 \mathrm{H}), 1.36(\mathrm{~d}, J=7.2 \mathrm{~Hz}, 3 \mathrm{H}) ;{ }^{13} \mathrm{C}$ NMR $(100 \mathrm{MHz}$, DMSO- $\left.d_{6}\right) \delta: 173.2,167.5,155.0,153.5,152.4,147.9$, $147.7,137.2,123.8,119.2,117.1,116.9,109.0,108.1$, 104.7, 68.5, 56.5, 52.5, 47.9, 17.5; IR (KBr) v: 3356, 3230, 2939, 1732, 1627, 1501, 1426, 1229, 1147, 1056, 1001, 852, 782, $555 \mathrm{~cm}^{-1}$; HRMS (ESI-MS) calcd for $\mathrm{C}_{21} \mathrm{H}_{20} \mathrm{ClFN}_{4} \mathrm{O}_{5}[\mathrm{M}+\mathrm{H}]^{+}$463.1176, found 463.1178.

4-(3-氯-4-氟苯胺基)-7-甲氧基-6-[氧代乙酰胺基$(L)$ - 苯丙胺酸甲酯]喹啉 $(8 \mathrm{n})$ : 白色固体, 产率 $74.6 \%$. m.p. $223.3 \sim 224.7^{\circ} \mathrm{C}$; ${ }^{1} \mathrm{H}$ NMR (400 MHz, DMSO- $d_{6}$ ) $\delta$ : 9.47 (s, 1H), 8.54 (s, 1H), 8.19 (d, $J=7.7 \mathrm{~Hz}, 1 \mathrm{H}), 8.11$ (dd, $J=6.8,2.5 \mathrm{~Hz}, 1 \mathrm{H}), 7.87 \sim 7.72(\mathrm{~m}, 2 \mathrm{H}), 7.46$ (t, $J=$ $9.1 \mathrm{~Hz}, 1 \mathrm{H}), 7.26 \sim 7.14(\mathrm{~m}, 6 \mathrm{H}), 4.72(\mathrm{t}, J=8.5 \mathrm{~Hz}, 2 \mathrm{H})$, $4.65(\mathrm{dt}, J=8.0,5.4 \mathrm{~Hz}, 1 \mathrm{H}), 3.96(\mathrm{~s}, 3 \mathrm{H}), 3.64(\mathrm{~s}, 3 \mathrm{H})$, $3.08(\mathrm{dd}, J=13.8,6.9 \mathrm{~Hz}, 2 \mathrm{H}) ;{ }^{13} \mathrm{C}$ NMR $(100 \mathrm{MHz}$, DMSO- $\left.d_{6}\right) \delta: 172.0,167.8,154.9,153.5,152.4$ 147.9, $137.2,129.5,123.8,122.5,119.2,116.9,109.0,108.1$, 104.5, 68.4, 56.5, 53.6, 52.5, 36.9; IR (KBr) v: 3407, 3353, 3029, 2950, 2838, 1729, 1627, 1501, 1434, 1231, 1141, 998, 855, 754, 701, $555 \mathrm{~cm}^{-1}$; HRMS (ESI-MS) calcd for $\mathrm{C}_{27} \mathrm{H}_{24} \mathrm{ClFN}_{4} \mathrm{O}_{5}[\mathrm{M}+\mathrm{H}]^{+}$539.1499, found 539.1495.

4-(3-氯-4-氟苯胺基)-7-甲氧基-6-[氧代乙酰胺-( $L$ )甲硫氨酸甲酯]喹啉 $(80)$ : 白色固体, 产率 $72.7 \%$. m.p. $223.9 \sim 224.7{ }^{\circ} \mathrm{C} ;{ }^{1} \mathrm{H}$ NMR (400 MHz, DMSO- $d_{6}$ ) $\delta: 9.49$ (s, 1H), 8.52 (s, 1H), 8.38 (d, $J=7.9 \mathrm{~Hz}, 1 \mathrm{H}), 8.10$ (dd, $J=6.8,2.6 \mathrm{~Hz}, 1 \mathrm{H}), 7.84$ (s, 1H), 7.77 (dd, $J=9.0,4.2 \mathrm{~Hz}$, $1 \mathrm{H}), 7.45$ (t, $J=9.1 \mathrm{~Hz}, 1 \mathrm{H}), 7.25(\mathrm{~s}, 1 \mathrm{H}), 4.81 \sim 4.71(\mathrm{~m}$, 2H), 4.54 (dd, $J=8.3,5.1 \mathrm{~Hz}, 1 \mathrm{H}), 3.97$ (s, 3H), 3.64 (s,
$3 \mathrm{H}), 2.49 \sim 2.40(\mathrm{~m}, 2 \mathrm{H}), 2.06 \sim 1.94(\mathrm{~m}, 5 \mathrm{H}) ;{ }^{13} \mathrm{C} \mathrm{NMR}$ $\left(100 \mathrm{MHz}\right.$, DMSO- $\left.d_{6}\right) \delta: 172.4,167.9,156.6,153.5,152.5$, $147.8,137.2,123.8,122.7,119.4,117.1,109.0,108.1$, 104.5, 68.4, 56.4, 52.6, 51.2, 30.8, 29.6, 15.0; IR (KBr) $v$ : $3355,3216,2917,2838,1742,1648,1500,1425,1209$, 1143, 1000, 858, 786, $548 \mathrm{~cm}^{-1}$; HRMS (ESI-MS) calcd for $\mathrm{C}_{23} \mathrm{H}_{24} \mathrm{ClFN}_{4} \mathrm{O}_{5} \mathrm{~S}[\mathrm{M}+\mathrm{H}]^{+}$523.1210, found 523.1214.

\section{9 吉非替尼衍生物 $9 \mathrm{a} \sim 9 \mathrm{~d}$ 的合成}

向 $100 \mathrm{~mL}$ 三颈瓶中依次加入 $N, N$-二甲基甲酰胺 DMF $20 \mathrm{~mL}, 4-(3$-氯-4-氟苯胺)-7-甲氧基-喹唑啉-6 醇 $0.7 \mathrm{~g}(2.2 \mathrm{mmol})$, 氮乙酰化氨基酸或二肽 $(4.4 \mathrm{mmol})$. 降 温至 $0{ }^{\circ} \mathrm{C}$, 依次加入 $\mathrm{TBTU} 1.4 \mathrm{~g}(4.4 \mathrm{mmol}), N$-甲基吗 啉 $0.45 \mathrm{~g}(4.4 \mathrm{mmol})$. 搅拌保持 $0{ }^{\circ} \mathrm{C}$ 反应 $0.5 \mathrm{~h}$ 后恢复至 室温搅拌 8 10 h, TLC 跟踪至原料点消失, 停止反应, 将反应液倒入水中有固体析出, 抽滤, 得固体粗产物通 过柱层析 $[V$ (乙酸乙酯) $: V$ (石油醚) $=1: 5 \sim 8$ ]分离得到 化合物 9a $\sim 9$ d.

4-(3-氯-4-氟苯胺基)-7-甲氧基-6-( $N$-乙酰甘氨酸酯) 喹啉(9a): 白色固体, 产率 67.2\%. m.p. $232.2 \sim 234.6{ }^{\circ} \mathrm{C}$; ${ }^{1} \mathrm{H}$ NMR (400 MHz, DMSO- $d_{6}$ ) $\delta: 9.75$ (s, 1H), 8.59 (s, $1 \mathrm{H}), 8.51(\mathrm{t}, J=5.8 \mathrm{~Hz}, 1 \mathrm{H}), 8.31$ (s, 1H), 8.18 (dd, $J=$ 6.8, $2.4 \mathrm{~Hz}, 1 \mathrm{H}), 7.91 \sim 7.70(\mathrm{~m}, 1 \mathrm{H}), 7.40$ (dd, $J=21.0$, $11.9 \mathrm{~Hz}, 2 \mathrm{H}), 4.19$ (d, J=5.9 Hz, 2H), 3.93 (s, 3H), 1.91 (s, $3 \mathrm{H}) ;{ }^{13} \mathrm{C}$ NMR (100 MHz, DMSO- $\left.d_{6}\right) \delta: 170.4,169.1$, $157.3,155.8,155.2,150.7,139.4,137.0,122.6,119.4$, 117.2, 116.5, 109.1, 109.0, 56.9, 22.7; IR (KBr) v: 3401, 3298, 3123, 2983, 2839, 1760, 1630, 1499, 1427, 1671, $1242,1164,1004,822,690,536 \mathrm{~cm}^{-1}$; HRMS (ESI-MS) calcd for $\mathrm{C}_{20} \mathrm{H}_{18} \mathrm{ClFN}_{4} \mathrm{O}_{5}[\mathrm{M}+\mathrm{H}]^{+}$419.0924, found 419.0920 .

4-(3-氯-4-氟苯胺基)-7-甲氧基-6- $[(L)-N$-乙酰亮氨酸 酯]喹啉(9b): 白色固体, 产率 77.4\%. m.p. 224.4 $225.8{ }^{\circ} \mathrm{C} ;{ }^{1} \mathrm{H}$ NMR (400 MHz, DMSO- $d_{6}$ ) $\delta$ : $9.78(\mathrm{~s}, 1 \mathrm{H})$, 8.59 (s, $1 \mathrm{H}), 8.47(\mathrm{~d}, J=7.6 \mathrm{~Hz}, 1 \mathrm{H}), 8.29$ (s, $1 \mathrm{H}), 8.17$ (dd, $J=6.9,2.6 \mathrm{~Hz}, 1 \mathrm{H}), 7.78$ (dd, $J=9.0,4.3,2.7 \mathrm{~Hz}$, 1H), 7.42 (t, $J=9.1 \mathrm{~Hz}, 1 \mathrm{H}), 7.35$ (s, 1H), 4.60 (dd, $J=$ 8.1, $6.4 \mathrm{~Hz}, 1 \mathrm{H}), 3.92$ (s, 3H), 1.90 (s, 3H), 1.77 (dd, $J=$ $14.3,7.4 \mathrm{~Hz}, 3 \mathrm{H}), 0.95(\mathrm{dd}, J=19.9,5.8 \mathrm{~Hz}, 6 \mathrm{H}) ;{ }^{13} \mathrm{C}$ NMR (100 MHz, DMSO- $\left.d_{6}\right) \delta: 171.6,170.1,157.4,155.7$, $155.1,152.5,150.7,139.6,137.0,122.7,119.3,117.1$, $116.5,109.1,108.9,56.9,50.7,24.8,23.3,22.7,21.7$; IR (KBr) $v$ : 3316, 3223, 3061, 2953, 1761, 1633, 1503, 1430, 1343, 1232, 1141, 1001, 925, 862, 693, $558 \mathrm{~cm}^{-1}$; HRMS (ESI-MS) calcd for $\mathrm{C}_{23} \mathrm{H}_{24} \mathrm{ClFN}_{4} \mathrm{O}_{4}[\mathrm{M}+\mathrm{H}]^{+}$475.1544, found 475.1548 . 
4-(3-氯-4-氟苯胺基)-7-甲氧基-6-[( $L)-N$-乙酰亮氨 酸- $(L)$ - 苯丙氨酸酯]喹啉 $(9 \mathrm{c})$ : 白色固体, 产率 $69.7 \%$. m.p. $255.3 \sim 257.2{ }^{\circ} \mathrm{C} ;{ }^{1} \mathrm{H}$ NMR (400 MHz, DMSO- $d_{6}$ ) $\delta$ : $9.80(\mathrm{~s}, 1 \mathrm{H}), 8.70(\mathrm{~d}, \quad J=8.5 \mathrm{~Hz}, 1 \mathrm{H}), 8.63(\mathrm{~s}, 1 \mathrm{H}), 8.35$ (s, $1 \mathrm{H}), 8.20(\mathrm{dd}, J=6.8,2.6 \mathrm{~Hz}, 1 \mathrm{H}), 7.91(\mathrm{~d}, J=8.5 \mathrm{~Hz}$, $1 \mathrm{H}), 7.86 \sim 7.77(\mathrm{~m}, 1 \mathrm{H}), 7.48 \sim 7.21(\mathrm{~m}, 7 \mathrm{H}), 4.91 \sim 4.82$ (m, $1 \mathrm{H}), 4.35(\mathrm{dd}, \quad J=9.0,5.8 \mathrm{~Hz}, 1 \mathrm{H}), 3.98(\mathrm{~s}, 3 \mathrm{H}), 3.40$ (dd, $J=13.8,3.9 \mathrm{~Hz}, 2 \mathrm{H}), 3.08$ (dd, $J=13.4,11.5 \mathrm{~Hz}, 1 \mathrm{H}$ ), $1.81(\mathrm{~s}, 3 \mathrm{H}), 1.35 \sim 1.27(\mathrm{~m}, 1 \mathrm{H}), 1.15 \sim 1.08(\mathrm{~m}, 1 \mathrm{H})$, $0.76(\mathrm{t}, J=6.1 \mathrm{~Hz}, 6 \mathrm{H}) ;{ }^{13} \mathrm{C}$ NMR $\left(100 \mathrm{MHz}, \mathrm{DMSO}-d_{6}\right)$ $\delta: 173.0,170,6,169.4,157.4,155.8,155.2,150.8,139.5$, 137.4, 137.0, 129.8, 119.4, 117.2, 116.5, 109.1, 57.0, 53.7, 51.2, 41.7, 37.2, 24.5, 23.3, 22.1; IR (KBr) v: 3392, 3302, 2966, 1751, 1647, 1500, 1426, 1390, 1241, 1161, 1002, $852,701,541 \mathrm{~cm}^{-1}$; HRMS (ESI-MS) calcd for $\mathrm{C}_{32} \mathrm{H}_{33} \mathrm{Cl}-$ $\mathrm{FN}_{5} \mathrm{O}_{5}[\mathrm{M}+\mathrm{H}]^{+} \quad 622.2248$, found 622.2243 .

4-(3-氯-4-氟苯胺基)-7-甲氧基-6- $[(L)-N$-乙酰甘氨 酸- $(L)$ - 苯丙氨酸酯]喹啉 $(9 d)$ : 白色固体, 产率 $79.4 \%$. m.p. $276.3 \sim 278.7{ }^{\circ} \mathrm{C} ;{ }^{1} \mathrm{H}$ NMR (400 MHz, DMSO- $d_{6}$ ) $\delta$ : $9.80(\mathrm{~s}, 1 \mathrm{H}), 8.69 \sim 8.53(\mathrm{~m}, 2 \mathrm{H}), 8.33(\mathrm{~s}, 1 \mathrm{H}), 8.19(\mathrm{dd}$, $J=6.7,2.2 \mathrm{~Hz}, 1 \mathrm{H}$ ), 8.08 (t, $J=5.6 \mathrm{~Hz}, 1 \mathrm{H}), 7.84 \sim 7.78$ (m, $1 \mathrm{H}), 7.50 \sim 7.22(\mathrm{~m}, 7 \mathrm{H}), 4.85(\mathrm{dd}, J=9.4,4.5 \mathrm{~Hz}$, 1H), $3.96(\mathrm{~s}, 3 \mathrm{H}), 3.80(\mathrm{dd}, J=16.8,5.9 \mathrm{~Hz}, 1 \mathrm{H}), 3.65(\mathrm{dd}$, $J=16.8,5.6 \mathrm{~Hz}, 1 \mathrm{H}), 3.39$ (d, $J=4.5 \mathrm{~Hz}, 1 \mathrm{H}), 3.11$ (dd, $J=13.8,10.1 \mathrm{~Hz}, 1 \mathrm{H}), 1.86(\mathrm{~d}, J=8.5 \mathrm{~Hz}, 3 \mathrm{H}) ;{ }^{13} \mathrm{C} \mathrm{NMR}$ $\left(100 \mathrm{MHz}\right.$, DMSO- $\left.d_{6}\right) \delta: 170.4,170.1,170.0,169.9,155.7$, $152.5,150.8,139.5,137.5,129.7,119.4,116.5,109.1$, 108.9, 56.9, 53.9, 42.1, 37.1, 22.9; IR (KBr) v: 3290, 3026, 2835, 1772, 1656, 1503, 1426, 1342, 1230, 1153, 1027, 931, 840, 699, $552 \mathrm{~cm}^{-1}$; HRMS (ESI-MS) calcd for $\mathrm{C}_{28} \mathrm{H}_{25} \mathrm{ClFN}_{5} \mathrm{O}_{5}[\mathrm{M}+\mathrm{H}]^{+}$566.1606, found 566.1609.

\subsection{0 抗肿瘤细胞毒活性实验}

采用溴化噻唑蓝四氮唑比色法(MTT)测试化合物 $7 a \sim 7 d, 8 a \sim 80$ 和 9a $\sim 9 d$ 对人非小细胞肺癌细胞 (A549)、人肝癌细胞(HepG-2)的体外抑制活性实验. 取 处于对数生长期的状态良好的细胞一瓶, 加入 0.25 (wt)\%胰蛋白酶消化液消化, 使贴壁细胞脱落, 计数, 制 成 $(2 \sim 4) \times 10^{4}$ 个细胞 $/ \mathrm{mL}$ 的悬液. 接种于 96 孔板上, $180 \mu \mathrm{L} /$ 孔, 置恒温 $\mathrm{CO}_{2}$ 培养箱中培养 $24 \mathrm{~h}$, 换液, 加入 受试化合物的 DMSO 溶液, $20 \mu \mathrm{L} /$ 孔, 再加入含体积分 数为 $10 \%$ 的血清培养液 $80 \mu \mathrm{L}$, 培养 $48 \mathrm{~h}$, 将 MTT 加入 96 孔板中, $20 \mu \mathrm{L} /$ 孔, 培养箱中反应 $4 \mathrm{~h}$. 吸去上清液, 加入 $\mathrm{DMSO}, 150 \mu \mathrm{L} /$ 孔, 平板摇床上振摇 $5 \mathrm{~min}$. 用酶联
免疫检测仪在波长为 $570 \mathrm{~nm}$ 处测定每孔的吸光值 $(\mathrm{OD}$ 值), 并计算对细胞增殖的抑制率. 以相应溶媒作阴性 对照, 以吉非替尼为阳性对照, 公式: 抑制率 $=[$ (阴性 对照组 OD 值一受试物组 OD 值)/阴性对照组 OD 值] $\times 100 \%$, 计算不同浓度下的抑制率, 再以此求出值 各样品的 $\mathrm{IC}_{50}$ (见表 1).

辅助材料(Supporting Information) 所有目标化合物 的 IR, ${ }^{1} \mathrm{H}$ NMR, ${ }^{13} \mathrm{C}$ NMR, HRMS 图谱. 这些材料可以免 费从本刊网站(http://sioc-journal.cn/)上下载.

\section{References}

[1] Ciardiello, F.; Caputo, R.; Bianco, R.; Damiano, V.; Pomatico, G.; Placido, S. D.; Bianco, A. R.; Tortora, G. Clin. Cancer Res. 2000, 6, 2053.

[2] Moasser, M. M.; Basso, A.; Averbuch, S. D.; Rosen, N. Cancer Res. 2001, 61, 7184.

[3] Friedmann, B.; Caplin, M.; Hartley, J. A.; Hochhauser, D. Clin. Cancer Res. 2004, 10, 6476.

[4] Chang, G.-C.; Hsu, S.-L.; Tsai, J.-R.; Liang, F.-P.; Lin, S.-Y.; Sheu, G.-T.; Chen, C.-Y. Biochem. Pharmacol. 2004, 68, 1453.

[5] Lee, E. J.; Whang, J. H.; Jeon, N. K.; Kim, J. Ann. N. Y. Acad. Sci. 2007, 1095, 113.

[6] Palmer, B. D.; Trumpp, S. J. Med. Chem. 1997, 40, 1519.

[7] Trumpp, S.; Rubin, J. R. J. Med. Chem. 1998, 41, 1752.

[8] Wissner, A.; Berger, D. M.; Boschelli, D. H.; Floyed, M. B.; Greenberger, Jr. L.M.; Gruber, B. C.; Johnson, B. D.; Mamuya, N.; Nilakantan, R.; Reich, M. F.; Shen, R.; Tsou, H. R.; Upeslacis, E.; Wang, Y. F.; Wu, B.; Ye, F.; Zhang, N. J. Med. Chem. 2000, 43, 3244.

[9] Wissner, A.; Overbeek, E.; Reich, M. F.; Floyd, M. B.;Johnson, B D.; Mamuya, N.; Rosfjord, E. C.; Discafan, C.; Davis, R.; Shi, X. Q.; Rabindran, S. K.; Gruber, B. C.; Ye, F.; Hallett, W. A.; Nilakantan, R.; Shen, R.; Wang, Y. F.; Greenberger, L. M.; Tsou, H. R. J. Med. Chem. 2003, 46, 49.

[10] Lee, J. Y.; Park, Y. K.; Seo, S. H.; So, I.-S.; Chung, H.-K.; Yang, B.-S.; Lee, S. J.; Park, H.; Lee, Y. S. Arch. Pharm. Pharm. Med. Chem. 2001, 334, 357.

[11] Lee, J.-Y.; Lee, Y.-S.; Park, H.-K.; Seo, S.-H.; Yang, B.-S.US 2003045537, 2003 [Chem. Abstr. 2003, 138, 122652c].

[12] Hou, T.-J.; Zhu, L.-L.; Chen, L.-R.; Xu, X.-J. Acta Chim. Sinica 2002, 60, 1023 (in Chinese) (侯廷军, 朱丽荔, 陈丽蓉, 徐䈗杰, 化学学报, 2002, 60, 1023.)

[13] Kobayashi, S.; Boggon, T. J.; Dayaram, T.; Janne, P. A.; Kocher, O.; Meyerson, M.; Johnson, B. E.; Eck, M. J.; Tenen, D. G.; Halmos, B. N. Engl. J. Med. 2005, 352, 786.

[14] Gibson, K. H.; Grundy, W.; Godfrey, A. A.; Woodburn, J. R.; Ashton, S. E.; Curry, B. J.; Scarlett, L.; Barker, A. J.; Brown, D. S. Bioorg. Med. Chem. Lett. 1997, 7, 2723.

[15] Gibson, K. H. WO 9633980, 1996 [Chem. Abstr. 1996, 126, 47235].

[16] Du, P.; Pan, C.-Y.; Peng D.-M. Chin. J. New Drugs 2006, 21(15), 1849 (in Chinese).

(杜鹏，潘春跃，彭东明，中国药学杂志, 2006, 21(15), 1849.) 